\title{
Exploring the sustainable logistics innovation process
}

Maria Björklund and Helena Forslund

The self-archived postprint version of this journal article is available at Linköping University Institutional Repository (DiVA):

http:// urn.kb.se/ resolve?urn=urn:nbn:se:liu:diva-145156

N.B.: When citing this work, cite the original publication.

Björklund, M., Forslund, H., (2018), Exploring the sustainable logistics innovation process, Industrial management + data systems, 118(1), 204-217. https:/ / doi.org/ 10.1108/ IMDS-02-2017-0058

Original publication available at:

https:// doi.org/10.1108/IMDS-02-2017-0058

Copyright: Emerald

http:// www.emeraldinsight.com/ 


\title{
Exploring the sustainable logistics innovation process
}

\begin{abstract}
Purpose -The development of more sustainable logistics calls for innovative thinking. In order to accelerate the development in the field, there is a need for increased understanding of the process behind successful implementation of sustainable logistics innovations (SLI). The purpose of this paper is to explore the SLI process, in order to identify critical factors, challenges as well as actors involved.

Design/methodology/approach - A multiple-case study in six Swedish retailers and LSPs, successful in SLI implementations, was conducted. Both within-case and cross-case analyses were applied.

Findings -The SLI process consists of five phases. The positive relationship between formalisation and SLI success is supported. Critical activities and challenges not known from literature were found in each phase. Examples are the use of logistics and customer KPIs, quickness, developing simple concepts, using a sustainability business case template and selecting where to test SLIs. Some phases are involving many internal and external actors, while others involve few internal actors. Customers are not particularly involved, and retailers involve their LSP suppliers.

Research implications - This study addresses the lack of empirical research in logistics innovation and has bridged the gap of innovation studies in other companies than in LSPs. Furthermore it has combined two developing areas, sustainable innovation and logistics innovation, into SLI. A number of critical activities and challenges, and complex patterns for actors' involvement in the SLI process phases are explored as insights from particular cases; these results could be analytically generalised to theory.

Practical implications - The practical implications lie in guiding managers who wish to improve sustainability and innovativeness in logistics and, consequently, business success. Knowledge from successful companies about which phases to go through in which sequence, which challenges that can be expected and who to include in the SLI process could imply that more companies focus on SLI.

Societal implications - Knowledge on how to include sustainability in a clear innovation process e.g. by making strong business cases, should imply an accelerated development of sustainable logistics in society.

Originality/value - This study addresses the lack of empirically-based research in logistics innovation and expands the concept to retailers.
\end{abstract}

Keywords Sustainable logistics, Innovation process, Case study, Innovation management

Paper type Research paper 


\section{Introduction}

Innovation is a key driver to sustainability in supply chains (Roscoe et al., 2016). Innovations within sustainability can significantly affect firm performance due to their positive impact on market share and reputation (Lin et al., 2014) and can therefore be incomegenerating. Applications of sustainability concepts in logistics have developed during the years (Piecyk and Björklund, 2015), and it is highly relevant for theory and practice to accelerate this development. Logistics innovation studies focus on logistics service providers (LSPs) (e.g. Rossi et al., 2013; da Mota Pedrosa et al., 2015; Marchet et al., 2017), and the same can be said regarding the logistical focus in the sustainable innovation literature (Zailani et al., 2011). Bringing these areas together implies focusing on sustainable logistics innovation (SLI). Inspired by the common innovation definition from OECD (2005, p. 46) and by Flint et al. (2005), SLI is defined as: "The implementation of a for-the-firm new, or significantly improved, service, process, or organisation in a logistics activity, that contributes to a more environmentally and/or socially sustainable development.” Logistics activities are not limited to executions in LSPs, thus studying SLIs in LSPs' transport activity is a narrow approach. A research gap is found, and expanded knowledge on SLI to consider other logistics activities is wished. In this study retailers are therefore included, as they manage several logistics activities and influence large parts of supply chains (e.g. Wiese et al., 2015).

If an organisation wants to be innovative, it needs to be able to manage innovation (Wagner and Sutter, 2012; Ota et al., 2013). Busse and Wallenburg (2011) stated that logistics innovation literature focus on innovation as a final result, while literature concerning how innovation emerges is lacking. de Medeiros et al. (2014) made similar claims regarding sustainable innovations. In line with Ota et al. (2013) and Arlbjørn et al. (2011, p. 6) claiming that firms "have to build a process that facilitates their pursuit of turning new ideas into products", a strong SLI process should be found behind companies' success in implementing SLIs. Few logistics innovation process studies are found (Su et al., 2011), and the same is valid for sustainable innovation process studies (Roscoe et al., 2016). Furthermore, Ota et al. (2013) noticed a research gap in that few innovation process studies are empirical.

No study on managing SLI was found. This study brings together the limited knowledge from logistics and sustainable innovation processes with empirical research, in order to contribute to the literature on the SLI process. As a clear process with certain underlying phases is likely to be associated with systematic success in SLIs (in parallel with Ota et al., 2013), there is a need to build deeper knowledge about this process. It is unclear if managing SLI differs from managing logistics or sustainable innovation. Are similar phases relevant? Not only should SLIs generate income, at the same time should it be cost-effective. What critical activities, enhancing the process, and challenges, hindering the process, are to be considered? A central aspect in logistics innovation studies (e.g. Marchet et al., 2017) is to involve actors, such as customers, in the process. Previous research has not clarified which actors to include in which phases in the SLI process? Addressing these questions imply knowledge on how to make the process contribute to company profitability, which in turn is valuable for the further development of SLIs. The purpose of this paper is to explore the SLI process, in order to identify critical activities, challenges, as well as actors involved.

\section{Literature review}

A literature review implies a selection involving the judgement of what to include and what to exclude from earlier research in the specific subject (Bryman and Bell, 2011) This review is mainly based upon logistics innovation and sustainable innovation studies. As few such studies were found, some general innovation process studies complement the review. This is a narrative 
rather than a systematic literature review (Bryman and Bell, 2011). The section is structured around innovation process phases, critical activities and challenges, and actors involved.

\subsection{Innovation process phases}

Logistics innovation studies present processes with phases. Flint et al. (2005) suggest a four-phase process: Setting the stage, laying a foundation for being innovative and creating an environment based on interacting with customers; Customer clue gathering, in which clues to changes in what customer values are sought; Negotiating, clarifying, and reflecting activities that lead to an understanding of what the customer actually wants, holding internal discussions of the clues found; and Inter-organisational learning for gaining insights and an increased understanding between LSP and customer organisations, co-producing innovations with customers through the active management of inter-organisational learning. In a more recent study of LSPs, da Mota Pedrosa et al. (2015) develop a four-phase process with other labels: Idea generation, to identify unfulfilled customer needs and generate ideas for new products/services; Concept development, to convert an idea into a concept that can be launched; Business analyses, for LSPs to analyse the potential success of the innovation and decide if the change ought to be implemented; and Implementation, to launch the innovation and develop additional features to improve it.

Sustainable innovation studies identified (e.g. Hockerts and Morsing, 2008; Rossi et al., 2013; de Medeiros et al., 2014; Roscoe et al., 2016) do not describe any particular phases. However, describing the process in phases provides a clear and sequential structure of activities taking place, and such a "backbone" therefore plays an important structuring role. General innovation studies (Hansen and Birkinshaw, 2007; Tidd and Bessant, 2009; Ota et al., 2013) present innovation processes with sequential phases and similar names. Ota et al. (2013) mean that innovation success comes from integrating these phases as a whole.

Looking for the least common denominator, four phases are suggested in the SLI process. They are labelled: Idea generation (including activities as setting the stage and customer clue gathering); Selection of ideas; Concept development (including activities as negotiating, clarifying, reflecting, business analyses); and Implementation and learning (including interorganisational learning). These phases form a structural basis for the empirical study. In the following sub-section, critical activities and challenges are linked to these phases.

\subsection{Critical activities and challenges}

Critical activities are activities that enhance the success in a particular phase or in the entire SLI process. Challenges can potentially hinder an activity, a phase, or the entire SLI process. Every critical activity has the potential to become a challenge, and a critical activity can also be a way to overcome a challenge. Thus, critical activities and challenges can be seen as different sides of the same coin.

Daugherty et al. (2011) studied logistics service innovation and found it to have a positive relationship both with decision-making decentralisation (decisions are delegated to middlelevel managers) and formalisation (following documented rules with routinized activities). They argued that formalisation does not "stifle" innovative approaches. This is critical related to the entire process rather than to a specific phase. As the studied companies' size and organisation differ a lot (from small Swedish to global companies) it is difficult to analyse in terms of centralisation/decentralisation. Therefore formalisation is focused.

Idea generation: A central, critical activity is that ideas are generated in different forms of customer interaction (seeking for clues, listening to, identify unfulfilled needs). Ayuso et al. (2011) expanded by concluding that dialogue with other stakeholders is important, however, this leads only to success if the company can absorb the information into their innovation process. Russo Spena and de Chiara (2012) recommended using sustainability indicators to 
generate ideas for innovation - another critical activity. Tidd and Bessant (2009) found high complexity due to many actors and therefore a challenge.

Selection of ideas: General innovation processes (Hansen and Birkinshaw, 2007; Tidd and Bessant, 2009; Ota et al., 2013) discuss how to select between ideas, indicating the need to manage many innovations. Challenges can be both to shut down new ideas due to conventional thinking and strict funding criteria, and to not apply criteria strictly enough resulting in underfunded innovations that do not fit company strategy. This challenge is not found in logistics innovation literature, indicating that the need for selection between ideas may be nonexistent. However, a selection can identify ideas of good quality related to available resources and can, therefore, play an important role. More importantly, sustainable innovation literature (e.g. Hockerts and Morsing, 2008; Rossi et al., 2013; de Medeiros et al., 2014; Roscoe et al., 2016) point out selection of ideas as a critical activity.

Concept development: This phase implies to convert a generated and selected idea into a concept that can be launched. A critical activity is to acquire knowledge, which can be described as deepening (the amount of knowledge a firm gathers in a specific area) and/or broadening (the number of areas in which a firm gathers knowledge); da Mota Pedrosa et al. (2015) suggested that these two strategies can be combined. Lin et al. (2010) also stressed the critical activity of information sharing and joint problem solving with customers and suppliers, as having significant impact on innovation development capabilities. Business analyses (da Mota Pedrosa et al., 2015) imply to analyse the potential success of the developed concept and decide if it should be implemented. General innovation literature rather labels this business case. "As we move to more radical innovation projects - which are by definition higher risk- so the 'business case' needs to be more strongly made ...to secure 'buy in' from decision-makers" (Tidd and Bessant, 2009, p. 317). Verloop (2004) claimed that going from general to sustainable innovation implies the selection of solutions not only out of a company perspective, but also the challenge to include other societal stakeholders, adding the social and environmental dimensions, which constitutes a sustainability business case. So first in this phase, logistics innovation literature has pointed at the need for selection. Firms need to constantly innovate to reduce harm to the environment and to the communities in which they operate. Innovations may increase the economic performance of the firm, but not necessarily lead to environmental or social performance (Roscoe et al., 2016). Therefore, all sustainability dimensions (social, environmental and economic) must be carefully assessed. da Mota Pedrosa et al. (2015) found a challenge in that employees with customer contacts were not involved in the business case, thus, the LSPs did not acquire customer knowledge. However, acquiring customer knowledge in this phase would increase the risk that sensitive knowledge becomes public.

Implementation and learning: Implementation is the final launch of the new service, process, or method, to an internal or external customer. Tidd and Bessant (2009) included reinnovation and upscaling in this phase. Hansen and Birkinshaw (2007) identified the critical activity that the relevant constituencies are given within the organisation to support the spread of innovations. In a sustainable logistics development study, Isaksson (2014) stressed the critical activity employee education. Learning also speaks to the critical activity of reflecting upon all phases in the process and reviewing the experiences of success and failure. Reflection is important in order to learn how to better manage the process, accumulating process knowledge and increase the efficiency in the process (Chapman et al., 2003). Flint et al. (2005) describe inter-organisational learning as a critical activity in the logistics innovation process for increased understanding between LSP and customers. Tidd and Bessant (2009) stated that even if researchers and practitioners see the importance of learning, it is a challenge to do in a structural way. 


\subsection{Actors involved in innovation processes}

The sustainable innovation literature brings in the notion of involving societal actors in assessing the value of an innovation, e.g. in a business case. In its supply chain context, the logistics innovation literature was early to stress the need of involving other actors. Flint et al. (2005) and Marchet et al. (2017) put forward the importance of customer interactions. Su et al. (2011) supplemented the Flint et al. (2005) model, and concluded that the logistics innovation process should also include suppliers. They claimed that logistics innovations are as dependent on internal stakeholders as on external relationships. Rossi et al. (2013) argued that sustainable innovations can strengthen relationships with customers into more long-lasting partnerships. Soosay et al. (2008) advocated collaboration with both customers and suppliers and, consequently, their resources and capabilities. One example is when suppliers carry out R\&D for the company and cover some of its costs. Also Lin et al. (2010) advocated involving both customers and suppliers. de Medeiros et al. (2014) concluded that the process should include both different actors in the firm and among external stakeholders, and especially stressed the importance of collaboration between the functions of different organisations. Similarly, Russo Spena and de Chiara (2012) discussed how to involve many departments in the innovation process. Flint et al. (2008) mentioned specifically logistics managers, who have insights into customer demands and can play important roles in the gathering, analysing, and dissemination of customer insights.

None of these studies recommend conducting the process company-internally. The literature seems to agree that the more actors involved in the process, the better. It is however not clear in which phases certain actors should or should not be involved. This is one important mission for the empirical study.

\section{Methodology}

This section contains information about research design, selection of case companies, data collection and analysis. Along the section, validity and reliability are discussed.

Research design: Research design refers to the execution of a research method (Bryman and Bell, 2011). This study has an exploratory purpose. Empirical input with possibilities to interact with company respondents is critical, and a case study approach is often appropriate (Yin, 2014). This multiple-case study was conducted to gather insights from particular cases. Such results could be analytically generalised to theory, and this theory could later be tested by replication (Yin, 2014).

Selection of case companies: The study object is the company, with the SLI process as an embedded unit. The wish was to find companies with a well-developed SLI process, which according to Ota et al. (2013) can be found in companies successful in SLI. Looking for companies that had won innovation awards in sustainable logistics or had presented SLIs in research projects, acting on the Swedish market and willing to participate, six companies representing retailers and logistics service providers were found. All companies see SLIs as business opportunities for competitive advantage and cost-reduction. The geographical context (Sweden) was chosen primarily based on convenience (Bryman and Bell, 2011) and the possibility to interview respondents personally and on site. Both retailers and LSPs were addressed; as indicated by previous studies LSPs fulfilled the selection criteria. The first contact person identified additional respondents involved in the SLI process. Using multiple respondents, or data triangulation (Yin, 2014), strengthens both validity and reliability. An overview of studied companies in terms of industry, size and respondents are shown in Table 1. 
Table 1. Overview of companies and respondents

\begin{tabular}{|l|l|l|}
\hline Company & Description & Respondents \\
\hline R1 & $\begin{array}{l}\text { Large grocery retail chain, operating in } \\
\text { Europe }\end{array}$ & $\begin{array}{l}\text { Logistics manager, CSR/sustainability manager, } \\
\text { Recycling manager }\end{array}$ \\
\hline R2 & $\begin{array}{l}\text { Large office supply retailer with } \\
\text { mainly B2B business, operating } \\
\text { globally }\end{array}$ & $\begin{array}{l}\text { Environmental and quality manager, Logistics } \\
\text { manager, Transport operation manager, Sales director }\end{array}$ \\
\hline R3 & $\begin{array}{l}\text { Small non-food retail chain, operating } \\
\text { in Sweden }\end{array}$ & $\begin{array}{l}\text { Supply chain manager, Logistics and transportation } \\
\text { manager }\end{array}$ \\
\hline LSP1 & $\begin{array}{l}\text { Medium-sized LSP operating in } \\
\text { Sweden }\end{array}$ & $\begin{array}{l}\text { Environmental and quality manager, Manager strategic } \\
\text { planning, Transport and distribution manager }\end{array}$ \\
\hline LSP2 & $\begin{array}{l}\text { Large LSP operating in the Nordic } \\
\text { countries }\end{array}$ & $\begin{array}{l}\text { Terminal manager, Environmental specialist, Senior } \\
\text { project leader technology and infrastructure, Train and } \\
\text { air freight manager }\end{array}$ \\
\hline LSP3 & Large LSP operating globally & $\begin{array}{l}\text { Senior product manager, Product manager domestic, } \\
\text { Sustainability manager, Sustainability specialist }\end{array}$ \\
\hline
\end{tabular}

Data collection: The data collection followed the procedures recommended by Yin (2014), such as basing the interview guide on the literature in order to increase construct validity. As the empirical study was central, the interview guide was semi-structured with open-ended questions. To ensure that respondents had relevant insights and responsibilities, they first described their background and then described some SLIs. The overall design of the SLI process was described with their own words, followed by a deeper description of each phase. Thereafter critical activities and challenges were discussed. The final part addressed the actors involved in each phase and activity. Twenty personal interviews (one with each respondent), lasting from 40 to 90 minutes, were conducted. Other data sources, such as sustainability reports and control documents (method triangulation - Yin, 2014), supplemented the interviews. Both authors participated in and took notes during the interviews. Then, the two authors' notes were consolidated and sent to each respondent for verification. The reliability of the study was further ensured by clearly documenting coding, decisions, and questions in a case study protocol (Yin, 2014).

Analysis: The interview guide eased the coding of the empirical data, which was done manually by the two authors in order to link critical activities, challenges and actors involved in the process phases. The verified interview notes, notes from other respondents in the same company, and other data built up the within-case analyses where phases, critical activities, challenges and actors involved are addressed. With a pattern-matching cross-case approach (Yin, 2014), the SLI processes in the cases are then compared to each other and to the literature. The exploratory purpose implies that empirically generated findings are discussed even if they are just found in one or few cases. An earlier scientific conference version of this paper was validated by all respondents, further strengthening validity and reliability.

\section{Within-case analysis}

The SLI processes are valid for different forms of SLIs, such as the following examples from the cases: a proactive transport planning system that ensures $100 \%$ fill rate in the trucks (organisational innovation); a purchasing tool making customers aware of the sustainability consequences of their purchasing behaviour, (service innovation); and a standing platform that enables the LSP to load the trucks higher and securing a healthy work environment (technical innovation).

\section{$4.1 R 1$}

The SLI process contains five phases 1 . identify problems 2 . brainstorm ideas 3 . find solutions 4 . quantify sustainability benefits and 5 . implement, follow up and spread. It has a 
"pre-phase" not found in literature; to actively identify problems. Furthermore no selection of ideas was conducted.

The process is described as well-documented and routinized, hence formalised. A large number of smaller and larger SLIs were implemented, supporting Daugherty et al. (2011) that formalisation does not "stifle" innovation. In identifying problems and generating ideas, a critical activity is to analyse not only sustainability KPIs, in line with Russo Spena and de Chiara (2012), but also the central logistics KPI fill rate. A critical activity not addressed in literature is to develop concepts that are easy to understand for employees, as the levels of education and language knowledge differ among staff in the warehouse and in the stores. In line with Tidd and Bessant (2009), the use of sustainability business cases are critical to secure "buy-in" from top management. However, in R1 this is critical also for smaller innovations, indicating an expanded need for business cases. Furthermore, formalized routines for spreading experiences (phase 5) to sister-companies was a critical activity, as even innovations with minor impact could be up-scaled, resulting in large total impact.

Internal actors are involved in the SLI process, such as different middle managers (phase 1). However, customers (Flint et al., 2005, Marchet et al., 2017) were not addressed to gain ideas for innovations. Universities, communities, energy companies and automotive manufacturers are involved in phase 2 and 3, the logistics manager (phase 4), and district managers as a channel to education needs and feedback from the stores in phase 5.

\section{$4.2 R 2$}

The SLI process consists of five phases 1 . need for change, 2. evaluate ideas, 3. build knowledge, 4. make business case, 5. implement and spread. Also here a pre-phase was found before idea generation, consisting of continuously identifying needs for change by monitoring logistics KPIs, such as fill rate, among sister-companies, employee suggestions and customers' needs via sellers.

The SLI process is well-documented, routinized, system-supported and therefore formalised. One challenge is to quickly let ideas reach management team evaluation, which is done weekly (phase 2), another is the design of the action team with a relevant mix of competencies and actors (phase 3). Especially critical is the activity to build trust with the LSPs, so they can develop together (phase 3). This is a sign of supplier collaboration and use of LSPs' resources as put forward by Soosay et al. (2008). The business case to the management team for smaller SLIs and to the European top-management for larger SLIs, is critical in line with Tidd and Bessant (2009). It is important in order for SLIs to compete with other investmentneeding initiatives. Spreading SLIs are done by delivering “one-pagers” on the intranet to sistercompanies.

Customers are important in identification of ideas (Flint et al., 2005; Marchet et al., 2017) as well as sister-companies, indicating that SLIs are as dependent on internal stakeholders as external relations (Lin et al., 2010; Su et al., 2011). The evaluation of ideas is carried out by the management team, while knowledge is built in collaboration between the action group and LSPs. The building of business case is carried out by the logistics manager and one reason for this is, in line with da Mota Pedrosa et al. (2015) not to risk that sensitive information becomes public.

\section{$4.3 R 3$}

The SLI process has four phases 1. capture ideas, 2. solve problems, 3. make business case and 4. implement. No selection of ideas was conducted, in line with e.g. da Mota Pedrosa et al. (2015). The process is not documented and informal. As this company was the one with the lowest number of implemented SLIs in the study, it can further support the findings of Daugherty et al. (2011) that formalisation is a critical "activity” in the SLI process. 
Several critical activities have been identified: to have open ears, walk around close to operations and to use logistics KPIs, such as fill rate, to generate ideas (phase 1). This is another expansion of Russo Spena and de Chiara (2012); not only focusing on sustainability KPIs. To form tailored groups of actors with high level of competency to solve problems or develop concepts (phase 2), is in line with knowledge deepening as suggested by da Mota Pedrosa et al. (2015). To make business cases, where the economic dimension has higher weight as R3 has a low-cost strategy conforms to Hansen and Birkinshaw (2007). Speed is considered critical in implementation.

Ideas are generated from a complexity of actors, such as internal employees, specialists, stores and external customers and LSPs, in line with Tidd and Bessant (2009). The problem solving is conducted by tailored internal teams and the business cases by business developers. The actors involved in the implementation are dependent on the type of SLI.

\subsection{LSP1}

The SLI process has four phases 1. identify ideas, 2. analyse ideas, 3. analyse funding, and 4. implement and upscale. The process is described as routinized and formalised by topmanagement, but un-formalised and not documented by those not directly involved. Formalisation is therefore not obviously high in LSP1.

Critical activities are the identification of ideas from logistics and sustainability KPIs, and that the idea analysis is closed in order not to spread information (da Mota Pedrosa et al., 2015). Analysing ideas has an interesting parallel approach, consisting of one centralised (topmanagement) and one decentralised (two middle managers) part. One related challenge is that it is unclear what selection criteria are applied in the respective processes, and in turn what kind of ideas to suggest. This is resulting in some mistrust for the process from those not directly involved. Another challenge identified is to decide which of the willing owners to test new solutions with.

Actors involved in identifying ideas are employees, managers, but seldom customers. The analysis of ideas and funding are either made centralised (by top-management) or decentralised (by two middle managers). As business risks are divided among owners, these play an important role in implementation.

\subsection{LSP2}

The SLI process has four phases 1. generate ideas, 2. solutions development, 3. make business case, and 4. implement, learn and spread). The process is routinized, following a project management tool and hence formalised. Critical activities identified in idea generation are monitoring sustainability KPIs, picking up signals from top-management and not decide on solutions too early. Another critical activity is to build teams with internal competencies, who often use external actors such as suppliers, for input in solutions development (phase 2). This shows that it is possible to keep sensitive information within the company, but at the same time gain the knowledge and experience from external actors in this phase. LSP2 has a central fund that analyses all SLI business cases. A critical activity is the use of a template, which ensures sustainability in all dimensions as well as the alignment with company strategy (Hansen and Birkinshaw, 2007).

Actors involved are the important role of the environmental specialists as speaking partners for managers in all levels. Customer input come via the business areas and the Key Account Managers, and from customer networks and workshops (phase 1). Customers as an important source in idea generation, is in line with e.g. Marchet et al. (2017). Other actors involved in idea generation are internal in the form of the managing director, employees and environmental specialists. Suppliers do on the other hand play an important role in developing solutions, in line with Su et al. (2011). The business case is made in collaboration between the idea owner, environmental specialists and the central fund, while the selection is made by the members in 
the fund only. Depending on the type of innovation different managers, as well as external actors can take part in the implementation.

\subsection{LSP3}

The SLI process consists of five phases 1 . analyse customer needs, 2. evaluate suggestions, 3. make business case, 4 . small-scale tests, 5 . implement, evaluate and learn. Phase 4 is not always a part of the process. It is formalised with specified rules and activities, and also systemsupported.

Critical activities are the active analysis of customer needs (phase 1) based on a satisfaction survey, to own and competitors' customers, and to ensure that the potential SLIs are discussed on higher levels within the organisation by one persons in the evaluation group (phase 2) also being member of the board. Another is in phase 5 , where the headquarter innovation department diffuse innovations top-down and ensure up-scaling. However, a challenge is that belonging to a global company also implies different environmental awareness, cultures, and cost structures among countries. One critical activity related to learning (phase 5) is the spreading of half-year reports, which contain all SLIs implemented.

The name of the first phase, analyse customer needs, clearly indicate the important role of involving customers. The internal sales organisation plays an important role in handling these ideas. This is very much in line with Ayuso et al. (2011) arguing for the important dialogue with external stakeholders in this phase, and furthermore the importance that the company can absorb this information in order to be successful in the innovation process. Some ideas for innovations come from the transport suppliers. An internal project group evaluate the suggestions with support from other actors such as sales and customer service (phase 2). All projects are managed by this group and each participant is the project leader for several projects. The project group are also active in the tests (phase 4), while a specified implementation group are involved in all implementations (phase 5).

\section{Cross-case analysis and discussion}

This section analyses the phases in the SLI process, then critical activities and challenges and finally actors involved, all summed up in Table 2 . In line with the purpose and method, all interesting findings are shown even if not found in many cases. Italic text denotes findings not found in literature.

Table 2. The SLI process phases, critical activities/challenges, and actors involved

\begin{tabular}{|l|l|l|}
\hline Phase & Critical activities and challenges & Actors involved \\
\hline All phases & Formalisation & \\
\hline $\begin{array}{l}\text { SLI idea generation } \\
\text { including proactively } \\
\text { searching for } \\
\text { problems/needs }\end{array}$ & $\begin{array}{l}\text { More interaction with customers } \\
\text { Handling complexity of many inputs } \\
\text { Using KPIs on sustainability/logistics/ } \\
\text { customer satisfaction }\end{array}$ & $\begin{array}{l}\text { A number of mainly internal actors } \\
\text { Little customer involvement }\end{array}$ \\
\hline Selection of ideas & $\begin{array}{l}\text { Communicate clear selection criteria } \\
\text { Quickness }\end{array}$ & Internal, managerial, closed \\
\hline Concept development & $\begin{array}{l}\text { Tailoring teams with deepening knowledge } \\
\text { Build trust with LSPs } \\
\text { Develop simple concepts }\end{array}$ & $\begin{array}{l}\text { A number of internal and external } \\
\text { actors }\end{array}$ \\
\hline $\begin{array}{l}\text { Making sustainability } \\
\text { business case } \\
\text { (separate phase) }\end{array}$ & $\begin{array}{l}\text { Evaluating economic, environmental and } \\
\text { social consequences of SLIs } \\
\text { Using a sustainability business case template } \\
\text { Ensuring alignment with strategy }\end{array}$ & Internal, managerial, closed. \\
\hline $\begin{array}{l}\text { Implementation and } \\
\text { learning }\end{array}$ & $\begin{array}{l}\text { Quickness } \\
\text { Selecting where to test SLIs } \\
\text { Reporting back successful SLIs }\end{array}$ & Internal \\
\hline
\end{tabular}




\subsection{Phases in the SLI process}

The studied companies described phases and sequences with large resemblance to innovation process literature, providing empirical support to the statements of Arlbjørn et al. (2011) and Ota et al. (2013) that innovative companies have a process for managing innovations. In R1 and R2, a "pre-phase" took place within generation of ideas were noted; their SLI processes started with a problem or need. This is seen as a proactive strive increasing the number of possible SLIs. Selection of ideas is not present in all cases. This is seen as a will not to disqualify ideas in a too early phase and rather do it when the concept is developed and there is a business case. The studied companies, successful in SLI, can be seen as forerunners with a wish to implement many SLIs.

The cases show that concept development consists of two different sub-phases: solutions development and making a business case to evaluate those solutions. In all cases this is seen as two distinct phases; therefore these are split up. Implementation and learning described together as a phase makes sense as companies could describe diffusion of SLIs, e.g. upscaling them to sister-companies/other parts of the organisation (in line with Tidd and Bessant, 2009) or developing additional features (da Mota Pedrosa et al., 2015) as a part of implementation or learning. The SLI process consists of five phases shown in the left column of Table 2.

\subsection{Critical activities and challenges}

This section is initiated with an analysis of formalisation of the SLI process, Daugherty et al. (2011) claimed that formalisation is positively related to innovation success, which this study confirms. Formalisation was found in the large companies studied, where formalisation can be expected. R3 is clearly un-formalised and the company with fewest SLIs. LSP1 has parallel phases going on; it seems as formalisation, rules and routines also in the smaller companies would increase SLI success. This is critical for the SLI process.

In line with Tidd and Bessant (2009), the idea generation phase is complex with many types of input, although little customer input (see further 5.3). Here, a managerial challenge is to secure that customer interests are better represented. The knowledge acquisition is characterised as broadening, using the terminology of da Mota Pedrosa et al. (2015). According to Ayuso et al. (2011), handling and absorbing this knowledge into the innovation process is a challenge. A link is seen to formalisation; there has to be a routinized way of handling this input. Examples are found in R2's system support and in LSP3 where the sales organisation plays an important role. One critical activity in all cases was the use of KPIs. Performance measurement is overlooked in the innovation literature (Russo Spena and de Chiara, 2012), who advocated the use of sustainability KPIs. Also other KPIs are applied, logistics (often related to fill rate - in R1, R2, R3, and LSP2), or customer satisfaction (LSP3). The use of broader KPIs is a critical activity in idea generation. The companies studied either do not select ideas or are seldom able to communicate selection criteria for the ideas (except for R2 and partly LSP2). This can generate mistrust within the organisation, and is a managerial challenge that needs to be addressed. R2 also expressed the criticality in quickly selecting ideas. Roscoe et al. (2016) indicated that sustainability dimensions can be applied as selection criteria in this phase, but this is not noted in the cases.

The challenge in concept development is mainly to tailor teams or groups with the accurate competency, in order to get deepening knowledge acquisition with the terminology of da Mota Pedrosa et al. (2015). To build trust with LSPs was especially critical for R2. In R1 an interesting challenge for concept development was found; that concepts had to be simple to understand and use. This was related to lower levels of education and language skills among operational staff. The making of a sustainability business case is expressed in all cases. This accords to Tidd and Bessant (2009), however, business cases are not just needed for radical SLIs. To gain internal support and the resources needed to develop ideas into reality, the project owner needs to show headquarter/top-management/board/central fund, that the idea is good for 
business from all sustainability dimensions (in accordance with Lin et al., 2014 and Roscoe et al., 2016). The business case is especially critical as SLIs have to compete with non-SLI initiatives for funding; it is critical to make sure that all sustainability gains are quantified to increase the competitiveness of SLIs. LSP2's central fund is a best-practice, it gives an overview, provides clear templates and develops the ability of the organisation to manage SLIs. Also this phase is clearly supported by formalisation (Daugherty et al., 2011). R3 and LSP2 point at yet another challenge: the SLI needs to be aligned with company strategy as mentioned by e.g. Hansen and Birkinshaw (2007). Some critical activities in implementation and learning were captured. The companies were seldom able to describe how SLIs were implemented, as this varies a lot; the same was found by Tidd and Bessant (2009). R3 stress the need to implement SLIs quickly. R1, LSP1, and LSP3 mention that sometimes the innovation needs to be tested before expanding to full scale. In LSP1, the importance of selecting with whom to test SLIs was noted. In accordance with Chapman et al. (2003) and Isaksson (2014), a need for better reflection and learning in the process is seen, pointing at a managerial challenge. This is mentioned by R1, LSP2 and LSP3. In the larger companies, successfully implemented SLIs are communicated back centrally on intranet or in reports. Then they are up-scaled to sistercompanies. Again, this is a phase in which formalisation supports innovation. Therefore formalisation of the SLI process is critical for SLI success. Critical activities and challenges are shown in the mid column of Table 2.

\subsection{Actors involved in the SLI process}

Broadening knowledge acquisition was found with different types of mainly internal actors in idea generation. Rossi et al. (2013) and Marchet et al. (2017) emphasised the involvement of customers, but such involvement is limited. R2, R3 and LSP2 mention customer involvement and LSP3 uses customer satisfaction measurements. Despite the fact that Flint et al. (2008) argued that logistics managers have important insights into customer demands, the studied logistics managers do not claim to deeply understand customer needs. Instead, sellers on different levels are highlighted as having this understanding. Russo Spena and de Chiara (2012) discussed the importance of involving many departments into the innovation process, which can be challenging enough. The selection of ideas phase can be described as company-internal and involving few actors. For respondents not directly involved in the process, this lack of insight generated mistrust for the process. Here, it suits to mention a limitation of the study, that mainly managers are addressed. It is likely that lower level employees perceive even more lack of insight, which may hinder potential SLIs to be handled.

To develop concepts from selected ideas, knowledge needs to be captured from many internal and external actors (de Medeiros et al., 2014). Examples of knowledge capturing from other actors not found in literature, such as communities, universities, energy companies and automotive manufacturers (R1) are found. All retailers and LSP2 support the important involvement of strategical LSPs in this phase, as proposed by Soosay et al. (2008) and Su et al. (2011). The making of sustainability business case implies that societal actors or stakeholders, such as environmental organisations, are addressed, in line with Roscoe et al. (2016), but they are not involved. One explanation to this is can be that the companies studied have own managers with deep environmental knowledge. It is handled internally in managerial groups or teams that may be closed. As it is in this phase that SLIs are selected or not selected, it would be interesting to involve customers here. What would happen if customers would be involved in selecting SLIs to implement? Implementation and learning is company-internal and can become somehow external when SLIs are spread to sister-companies or LSPs in the shape of inter-organisational learning (Flint et al., 2005).

The SLI process phases in the six companies, successful in SLI, consequently go "in waves". Many internal actors are involved in idea generation. Selection of ideas is involving few internal actors, concept development involves many internal and external actors. Both 
making a sustainability business case and implementation and learning is involving few internal actors. The complexity with actors involved is another managerial challenge to handle. This is shown in the right column of Table 2.

\section{Conclusions, implications and further research}

The purpose of this paper is to explore the SLI process, in order to identify critical activities, challenges, as well as actors involved. There is overall consensus between literature and the studied companies regarding the phases and sequence in the SLI process although two differences have been identified: that generating ideas can come from proactive identification of problems, and that the making of a sustainability business case is seen as a separate phase. The SLI process consists of idea generation, selection of ideas, concept development, make a sustainability business case and implementation and learning. The study supports the findings of Ota et al. (2013), who found that managing all phases as a whole is associated with innovation success. Critical for the SLI process is formalisation. This study supports the findings of Daugherty et al. (2011) of a positive relationship between formalisation and SLI success. Critical activities and challenges not known from literature were found in each phase. Examples are the use of logistics and customer KPIs, quickness, developing simple concepts, using a sustainability business case template and selecting where to test SLIs. Differences in actors involved (e.g. Lin et al., 2010; Ayuso et al., 2011) were found between phases, where some phases are involving many internal and external actors, while others involve so few internal actors that lack of insight was expressed. Customers are not particularly involved, and retailers involve their LSP suppliers.

This study has several research implications. It addresses the lack of empirical research in logistics innovation (see e.g. Arlbjørn et al., 2011; Ota et al., 2013) and it has bridged the gap of innovation studies in other companies than in LSPs. Furthermore it has combined two developing areas, sustainable innovation and logistics innovation, into SLI. A number of critical activities and challenges, and complex patterns for actors' involvement in the SLI process phases are explored as insights from particular cases; these results could be analytically generalised to theory. This study was carried out in Sweden. However, four of the case companies belong to international company groups, and all of them face international competition and act in international supply chains. Therefore, there is no reason why the findings should not be applicable also in the broader world of SCM.

The practical implications lie in guiding managers who wish to improve sustainability and innovativeness in logistics and, consequently, business success. SLIs can both generate income (Lin et al., 2011) and, managed in a clear process also potentially reduce cost. Knowledge from successful companies about which phases to go through in which sequence, which challenges that can be expected and who to include in the SLI process should imply that more companies focus on SLI. The study especially pinpoints some managerial challenges that need to be addressed, such as to include customers to a higher extent, to clearer communicate selection criteria, and to conduct sustainability business cases.

The sustainability focus implies societal implications. Knowledge on how to include sustainability in a clear innovation processes e.g. by strong business cases, should imply an accelerated development of sustainable logistics in society.

An obvious call for further research is to test the findings of this study by replication on a larger sample. No manufacturers were included in the study, which would be an interesting expansion. Another interesting area for further research is to study the potential profitability effects from implementing SLIs, as little such evidence exists. 


\section{Acknowledgements}

The founding authority will be entered after review.

\section{References}

Arlbjørn, J., S., de Haas, H. and Munksgaard, K., B. (2011) "Exploring supply chain innovation”, Logistics Research, Vol. 3 No. 3, pp. 3-18.

Ayuso, S., Rodríguez, M.Á., García-Castro, R. and Ariño, M.Á. (2011) "Does stakeholder engagement promote sustainable innovation orientation?", Industrial Management \& Data Systems, Vol. 111 No. 9, pp.1399-1417.

Bryman, A. and Bell, E. (2011). Business research methods (3rd ed.). Oxford University Press, New York.

Busse, C. and Wallenburg, C.M. (2011),"Innovation management of logistics service providers: Foundations, review, and research agenda", International Journal of Physical Distribution \& Logistics Management, Vol. 41 No. 2, pp. 187-218.

Chapman, R. L., Soosay, C. and Kandampully, J. (2003), "Innovations in logistics services and the new business model, a conceptual framework", International Journal of Physical Distribution \& Logistics Management, Vol. 33 No. 7, pp. 630-650.

Daugherty, P. J., Haozhe, C. and Ferrin, B.G. (2011),"Organizational structure and logistics service innovation", The International Journal of Logistics Management, Vol. 22 No. 1, pp. 2651.

de Medeiros, J.F., Ribeiro, J.L.D. and Cortimiglia, M.N. (2014), "Success factors for environmentally sustainable product innovation; a systematic literature review", Journal of Cleaner Production, Vol. 65, pp. 76-86.

da Mota Pedrosa, A., Blazevic, V. and Jasmand, C. (2015),'Logistics innovation development: a micro-level perspective”, International Journal of Physical Distribution \& Logistics Management, Vol. 45 No. 4, pp. 313-332.

Flint, D., J., Larsson, E., Gammelgaard, B. and Mentzer, J., T. (2005), "Logistics innovation: A customer value-oriented social process”, Journal of Business Logistics, Vol. 26 No. 1, pp. 113-147.

Flint, D., J., Larsson, E. and Gammelgaard, B. (2008), "Exploring processes for customer value insights, supply chain learning and innovation: an international study", Journal of Business Logistics, Vol. 29 No. 1, pp. 257-281.

Hansen, M.T. and Birkinshaw, J. (2007), “The innovation value chain”, Harvard Business Review, Vol. 85 No. 6, pp. 121-130.

Hockerts, K. and Morsing, M. (2008), A literature review on Corporate Social Responsibility in the innovation process, Copenhagen Business School, Center for CSR.

Isaksson, K. (2014), Logistics service providers going green - a framework for developing green service offerings, $\mathrm{PhD}$ thesis No. 1600, Linköping university.

Lin, R.J., Chen, R.H. and Chiu, K.K.S. (2010) "Customer relationship management and innovation capability: an empirical study", Industrial Management \& Data Systems, Vol. 110 No. 1, pp.111-133

Lin, R.J., Chen, R.H. and Huang, F.H. (2014) "Green innovation in the automobile industry", Industrial Management \& Data Systems, Vol. 114 No. 6, pp. 886-903.

Marchet, G., Melacini, M., Sassi, C. and Tappia, E. (2017) “Assessing efficiency and innovation in the 3PL industry: an empirical analysis”, International Journal of Logistics Research and Applications, Vol. 20 No. 1, pp. 53-72.

OECD (2005), Oslo Manual: guidelines for collecting and interpreting innovation data. $3^{\text {rd }}$ edition, OECD Publishing. 
Ota, M., Hazama, Y. and Samson, D. (2013), "Japanese innovation processes", International Journal of Operations \& Production Management, Vol. 33 No. 3, pp. 275-295.

Piecyk, M. and Björklund, M. (2015), Green logistics, sustainable development and corporate social responsibility, in Green Logistics: Improving the environmental sustainability of Logistics [ed] McKinnon, A., Cullinane, S., Whiteing, A., and Browne, M., Kogan page, pp. 107-118.

Roscoe, S. Cousins, P.D. and Lamming, R. C. (2016), "Developing eco-innovations: a three-stage typology of supply networks”, Journal of Cleaner Production, Vol. 112, pp. 19481959.

Rossi, S., Colicchia, C., Cozzolino, A. and Christopher, M. (2013), “The logistics service providers in eco-efficiency innovation: an empirical study", Supply Chain Management: An International Journal, Vol. 18 No.6, pp. 583-603.

Russo Spena, T. and de Chiara, A. (2012),"CSR, innovation strategy and supply chain management: towards an integrated perspective", International Journal of Technology Management, Vol. 58 No. 1/2, pp. 83-108.

Soosay, C. A., Hyland, P. W. and Ferrer, M. (2008),"Supply chain collaboration: capabilities for continuous innovation", Supply Chain Management: An International Journal, Vol. 13 No. 2, pp. 160-169

Su, S.I., Gammelgaard, B. and Yang, S.L. (2011) "Logistics innovation process revisited: insights from a hospital case study", International Journal of Physical Distribution \& Logistics Management, Vol. 41 No. 6, pp. 577-600.

Tidd, J. and Bessant, J. (2009), Managing innovation, Integrating technological, market and organizational change, $4^{\text {th }}$ edition, John Wiley \& Sons, West Sussex, England.

Verloop, J. (2004), Insight in innovation: managing innovation by understanding the laws of innovation, Elsevier, Amsterdam, Netherlands.

Wagner, S.M. and Sutter, R. (2012), “A qualitative investigation of innovation between 3PL providers and customers”, International Journal of Production Economics, Vol. 140, pp. 944-958.

Wiese, A., Zielke, S, and Toporowski, W. (2015), "Sustainability in retailing - research streams and emerging trends", International Journal of Retail \& Distribution Management, Vol. 43 No. 4/5, pp. 318-335.

Zailani, S., Amran, A. and Jumadi, H. (2011), "Green innovation adoption among logistics service providers in Malaysia: an exploratory study on the managers' perceptions”, International Business Management, Vol. 5 No. 3, pp. 104-113.

Yin, R. (2014). Case study research; design and methods. Sage Publishing, London. 